\title{
An evaluation of inflammatory gene polymorphisms in sibships discordant for premature coronary artery disease: the GRACE-IMMUNE study
}

\author{
Benjamin D Brown'1, Jérémie Nsengimana², Jennifer H Barrett², Richard A Lawrence1, Lori Steiner³, Suzanne Cheng³ , D \\ Timothy Bishop², Nilesh J Samani4, Stephen G Ball1, Anthony J Balmforth'1 and Alistair S Hall*1
}

\begin{abstract}
Background: Inflammatory cytokines play a crucial role in coronary artery disease (CAD). We investigated the association between 48 coding and three non-coding single nucleotide polymorphisms (SNPs) from 35 inflammatory genes and the development of CAD, using a large discordant sibship collection (2699 individuals in 891 families).

Methods: Family-based association tests (FBAT) and conditional logistic regression (CLR) were applied to single SNPs and haplotypes and, in CLR, traditional risk factors of CAD were adjusted for.

Results: An association was observed between CAD and a common three-locus haplotype in the interleukin one (IL-1) cluster with $P=0.006$ in all CAD cases, $P=0.01$ in myocardial infarction (MI) cases and $P=0.0002$ in young onset CAD cases $(<50$ years). The estimated odds ratio (OR) per copy of this haplotype is 1.21 (95\% confidence interval [95Cl] $=$ 1.04 - 1.40) for CAD; $1.30(95 \mathrm{Cl}=1.09-1.56)$ for $\mathrm{Ml}$ and $1.50(95 \mathrm{Cl}=1.22-1.86)$ for young onset CAD. When sex, smoking, hypertension and hypercholesterolaemia were adjusted for, the haplotype effect remained nominally significant $(P=0.05)$ in young onset CAD cases, more so $(P=0.002)$ when hypercholesterolaemia was excluded. As many as $82 \%$ of individuals affected by CAD had hypercholesterolaemia compared to only $29 \%$ of those unaffected, making the two phenotypes difficult to separate.
\end{abstract}

Conclusion: Despite the multiple hypotheses tested, the robustness of family design to population confoundings and the consistency with previous findings increase the likelihood of true association. Further investigation using larger data sets is needed in order for this to be confirmed.

See the related commentary by Keavney: http://www.biomedcentral.com/1741-7015/8/6

\section{Background}

Coronary atherosclerosis is predominantly an asymptomatic process that progresses over the course of a lifetime. Arterial inflammation is central to plaque progression and plaque rupture with atherosclerotic lesions established as active sites of inflammation [1]. In particular, cytokines appear to coordinate the development of atherosclerosis leading to the formation of complex atherosclerotic plaques. These, in turn, can trigger acute thromboembolic complications such as myocardial infarction (MI) and the

* Correspondence: a.s.hall@leeds.ac.uk

'Leeds Institute of Genetics, Health and Therapeutics (LIGHT), University of Leeds, UK rupture/repair process that promotes the progression of luminal narrowing [2]. Furthermore, those lesions conveying the greatest risk to the individual are characterized by a higher level of inflammation. Coronary atherosclerosis and its complications are a complex disorder resulting from the combined effects of multiple environmental and genetic factors. Whilst most traditional risk factors for coronary artery disease (CAD) are themselves heritable, a family history remains an independent predictor of this condition $[1,2]$. The aim of this study was to evaluate individual polymorphisms and haplotypes in inflammatory genes for association with an increased predisposition to CAD. In total, 51 single nucleotide polymorphisms (SNPs) were analysed 
in 35 inflammatory genes in a large cohort of discordant sibships recruited across the UK in the Genetic Risk of Acute Coronary Events (GRACE) study.

\section{Methods \\ Clinical methods}

The study was approved by the Multicentre (MREC) and Local Research Ethics Committees (LRECs) throughout the UK. The details of the recruitment process can be found in the Additional File 1. Premature CAD was defined as a validated MI, percutaneous transluminal coronary angioplasty (PTCA), coronary artery bypass surgery (CABG) or angina (exercise test positive or angiogram showing at least one lesion $>50 \%$ ) before the age of 66 . Hypercholesterolaemia was considered as either being on lipid lowering therapy or having total cholesterol greater than $4.9 \mathrm{mmol}^{\mathrm{l}^{-1}}$ for individuals with a previous $\mathrm{MI}$ or greater than $5.2 \mathrm{mmol} / \mathrm{l}$ for individuals with other affected phenotypes (PTCA, CABG or angina) and unaffected individuals. Hypertension was either being on therapy or a blood pressure greater than $150 / 90 \mathrm{mmHg}$.

\section{Genotyping}

Fifty SNPs and one insertion/deletion, mainly located in coding regions of 35 inflammatory genes, were genotyped (48 polymorphisms from coding regions and three from the introns). The primer mix and all other necessary components for the SNP genotyping were provided by Roche Molecular Systems (Pleasanton, USA). Characteristics of the polymorphisms are shown in the Additional File 2. DNA extraction and storage was performed using the PUREGENE ${ }^{\circledR}$ DNA extraction kit (available from Gentra Systems, MN, USA). A pooled polymerase chain reaction (PCR) amplified the chosen targets from $50 \mathrm{ng}$ of genomic DNA to produce biotin labelled products. These products were then hybridized with sequence specific oligonucleotide probes immobilized in a linear array. A series of development stages enabled detection of hybridization between probe and PCR product thus allowing identification of genotypes (homozygous wild, homozygous mutant, heterozygote). The processed strip was then scanned and genotypes were assigned by StripScan software (Roche Molecular Systems) [3] providing a semi-automated reading of the data assigning genotypes.

\section{Statistical analyses}

Family relationships were validated using the Graphical Representation of Relationships (GRR) and RELATIVE programs $[4,5]$ based on the 51 polymorphisms from this study plus 65 additional SNPs (analysis details in the Additional File 3). Allele frequencies were estimated using the program MENDEL which accounts for family relationships [6] and Hardy-Weinberg equilibrium was tested for each SNP using a goodness-of-fit test. The primary analysis was a test of association in presence of linkage between CAD and each individual SNP using the family-based association test (FBAT) [7]. We used the version of this test that employs empirical variance to account for residual familial correlation [8] (program FBAT 2.0.2C, option -e). An additive mode of inheritance was assumed. The analysis was repeated in two subsets of the data: (1) all cases affected with $\mathrm{MI}$ and their siblings and (2) all cases of CAD before the age of 50 and their siblings (see details in the Additional File 3). For genes or regions where two or more polymorphisms were in linkage disequilibrium (LD), haplotype analysis was also carried out in FBAT.

The haplotypes showing the highest evidence of association were further analysed using simple conditional logistic regression (CLR) in STATA [9], subsequently adding in clinical covariates. Robust variance was used to account for correlation between family members in CLR $[10,11]$. Haplotypes were inferred using the program HAPLORE [12]. As parents were not genotyped, there was some uncertainty in haplotype assignment. This uncertainty was accounted for in CLR by using a weighting approach originally designed for unrelated cases and controls [13] and adapted here to family data (see details in the Additional File 3). After identifying a haplotype associated with CAD, we used unconditional logistic regression to assess whether the same haplotype predicts hypercholesterolaemia, the most predominant clinical risk factor for $\mathrm{CAD}$ in our dataset.

\section{Results}

\section{Family structures and effects of clinical risk factors}

The initial data set consisted of 2870 individuals from 930 families. As a result of relationship checking, a total of 41 families were discarded - mainly because reported siblings were found to be more likely half-siblings. In addition, two families were each split into two, leaving a final sample size of 2699 persons from 891 families. The structure of the families included in this study is detailed in Table 1. The median age of disease onset was 50 years (range 21-66) and $69 \%$ of affected individuals had a MI as the index event. The median age of unaffected individuals was 57 years (range 35-85) and intra-family comparisons of ages revealed that over $80 \%$ of unaffected siblings had surpassed the age at which their affected siblings had their events. Clinical characteristics of the study sample are shown in Table 2.

Considered individually, each of the traditional risk factors of CAD [male gender, diabetes, hypertension, hypercholesterolaemia, cigarette smoking and body mass index (BMI)] has a highly significant effect on disease risk. When all these factors are included in the model jointly, male gender, hypertension, cigarette smoking and hypercholesterolaemia still show a highly significant effect on CAD, whilst diabetes mellitus has a borderline effect and BMI was not associated with CAD (Table 2). 
Table 1: Structure of families included in the study.

\begin{tabular}{|c|c|c|c|c|}
\hline \multirow[t]{2}{*}{ No. of affecteds } & \multirow[t]{2}{*}{ No. of unaffecteds } & \multicolumn{3}{|c|}{ No. of families with } \\
\hline & & CAD & CAD before 50 years* & MI † \\
\hline 1 & 1 & 164 & 149 & 122 \\
\hline 1 & 2 & 439 & 235 & 362 \\
\hline 1 & $>2$ & 49 & 38 & 39 \\
\hline 2 & 1 & 158 & 46 & 78 \\
\hline 2 & 2 & 42 & 15 & 23 \\
\hline 2 & $>2$ & 18 & 6 & 14 \\
\hline$\geq 3$ & $\geq 1$ & 21 & 4 & 11 \\
\hline Total families & & 891 & 493 & 660 \\
\hline Total affecteds & & 1154 & 568 & 802 \\
\hline Total unaffecteds & & 1545 & 855 & 1204 \\
\hline
\end{tabular}

\section{Family-based association tests for individual SNPs}

The results of SNP by SNP analysis are shown in Table 3. Results are reported only for SNPs that were in HardyWeinberg equilibrium and for which we had at least 50 informative families (the average number of informative families was 345). Associations with CAD significant at $5 \%$ level were found for polymorphisms in interleukin 9 [(IL9) C4244T, $P=0.01]$, nitric oxide synthase 3 [(NOS3) A498G, $P=0.05]$, complement component $5[(C 5)$ A2416G, $P=0.04]$, interleukin 4 receptor [(IL4R T1682C, $P=0.01$ and A1902G, $P=0.04]$ and eotaxin [(SCYA11) G361A, $P=0.04]$. In the subsets of MI cases and those with younger $\mathrm{CAD}$ onset ( $<50$ years) the associations with $C 5$ (A2416G) remained (MI only $P=0.006 ;<50$ years $P=$ $0.04)$ and additional significant associations were observed with interleukin 1 alpha $(I L 1 \alpha)$ C549T (MI only $P=0.02$; $<50$ years $P=0.02$ ).

\section{Haplotype analysis}

More than one SNP were genotyped within 13 genes and one gene cluster $(I L 1 \alpha-I L 1 \beta)$. Table 4 shows the genes or gene cluster where any haplotype was significantly associated with $\mathrm{CAD}, \mathrm{CAD}$ before 50 years or $\mathrm{MI}$ at the nominal $5 \%$ level using FBAT. The LD (measured with D') between adjacent SNPs is also shown along with their physical position from dbSNP build 128 . The most significantly associated haplotype was found in the ILI cluster (CCC haplotype, frequency of $41 \%$ in the total sample), which was found at increased frequency in all CAD cases $(P=$ $0.006)$, MI cases $(P=0.01)$ and young CAD cases $(P=$ $0.0002)$, although the overall haplotype effect only reached the $5 \%$ significance level in early-onset CAD cases $(P=$ 0.02 , with 7 degrees of freedom). In NOS3 gene, there was a significant protective effect of the AT haplotype (frequency $11 \%$ ) in overall CAD (single haplotype $P=0.009$ and overall test $P=0.04$ ) and in MI (single haplotype $P=$ 
Table 2: Clinical characteristics of the study sample.

\begin{tabular}{|c|c|c|c|c|}
\hline \multirow[b]{2}{*}{ Risk factor } & \multirow{2}{*}{$\begin{array}{l}\text { Unaffected } \\
\mathrm{N}(\%)\end{array}$} & \multicolumn{2}{|l|}{ Affected } & \multirow[b]{2}{*}{$\begin{array}{l}\text { Multivariable } \\
\text { ORt }\end{array}$} \\
\hline & & N (\%) & $\begin{array}{l}\text { Univariate } \\
\text { P-value * }\end{array}$ & \\
\hline Total sample & $1545(100)$ & $1154(100)$ & - & - \\
\hline Male sex & $630(40.8)$ & $873(75.7)$ & $<0.0001$ & $4.71(3.65,6.08)$ \\
\hline Diabetes mellitus & $62(4.0)$ & $117(10.1)$ & $<0.0001$ & $1.63(1.00,2.66)$ \\
\hline Hypertension & $391(25.3)$ & $522(45.2)$ & $<0.0001$ & $1.99(1.52,2.60)$ \\
\hline $\begin{array}{l}\text { Hypercholesterolae- } \\
\text { mia }\end{array}$ & $454(29.4)$ & $945(81.9)$ & $<0.0001$ & $10.70(8.11,14.11)$ \\
\hline Ever smoked & $856(55.4)$ & $849(73.6)$ & $<0.0001$ & $1.72(1.32,2.25)$ \\
\hline \multirow[t]{2}{*}{ BMI } & Mean (SD) & Mean (SD) & 0.0002 & $1.00(0.97,1.04)$ \\
\hline & $27.16(4.62)$ & $27.74(4.05)$ & & \\
\hline
\end{tabular}

* Univariate conditional logistic regression for binary factors and linear regression clustered by family for body mass index (BMI) † Odds ratio (OR) and $95 \%$ confidence intervals from multivariable conditional logistic regression analysis including all six factors SD: standard deviation

0.005 , overall test $P=0.03$ ). However, there was no evidence of haplotype association in this gene in younger disease onset. Other haplotypes with nominally significant effects were found in IL4R and SCYAII (Table 4).

\section{IL1 haplotype effect estimation}

Using an additive model with no covariate adjustment in weighted CLR, each copy of IL1-CCC haplotype confers an increase in risk of CAD with estimated odds ratio (OR) of $1.21[95 \%$ confidence interval $(95 \mathrm{CI})=1.04-1.40, P=$ $0.01]$ in the total sample. For young-onset cases, the estimated OR was $1.50(95 \mathrm{CI}=1.22-1.86, P=0.0001)$ and for $\mathrm{MI}$ the OR was 1.30 (95 $\mathrm{CI}=1.09-1.56, P=0.003)$. The overall significance level of all haplotypes (7df) was 0.28 in the whole sample, 0.18 for MI only and 0.02 in the affecteds before age 50 . When tested jointly with four clinical covariates (hypercholesterolaemia, hypertension, smoking and sex), the effect of haplotype ILI-CCC on CAD was no longer significant in the whole sample $(\mathrm{OR}=1.07, P=$ $0.57)$ nor in those affected by $\mathrm{MI}(\mathrm{OR}=1.26, P=0.07)$, but it was nominally significant in younger cases $(<50$ years $\mathrm{OR}=1.39, P=0.05)$. No significant interaction was found between IL1-CCC haplotype and any of the covariates.
The most potent predictor of increased risk of disease in our population was hypercholesterolaemia (see Table 2). When it was excluded from the multivariable analysis, the effect of haplotype ILI-CCC in the whole sample was significant $(\mathrm{OR}=1.22, P=0.05)$, and was more so in those with younger onset disease $(\mathrm{OR}=1.53, P=0.002$, see Table 5). This indicates a possible relationship between the haplotype and hypercholesterolaemia itself. In order to test this, a simple unconditional logistic regression analysis was carried out on the whole study population and stratifying by CAD, using hypercholesterolaemia as the trait of interest with IL1-CCC haplotype as predictor. In the whole dataset, the estimated OR of having hypercholesterolaemia was 1.15 (95 CI $=1.03-1.29$, unadjusted $P=0.01)$ per copy of haplotype IL1-CCC. This was comparable to the OR of developing CAD per copy the same haplotype using unconditional logistic regression $(\mathrm{OR}=1.21,95 \mathrm{CI}=1.02-1.43$, unadjusted $P=0.02$ ). The haplotype effect on hypercholesterolaemia was of the same magnitude in subjects affected and unaffected by CAD, although not significant in these smaller subsets $(\mathrm{OR}=1.10,95 \mathrm{CI}=0.88-1.37$ and $\mathrm{OR}=$ $1.13,95 \mathrm{CI}=0.96-1.33$, respectively). This result suggests 
Table 3: Tests of association between SNPs and CAD using FBAT.

\begin{tabular}{|c|c|c|c|c|c|}
\hline Chromosome & Gene & SNP & RS number & MAF & P-value * \\
\hline 1p32-p31 & VCAM1 & T707C & 1041163 & 0.16 & 0.39 \\
\hline \multirow[t]{2}{*}{$1 q 21-24$} & SELP & G40A & 6131 & 0.18 & 0.84 \\
\hline & & G75271T & 6133 & 0.14 & 0.67 \\
\hline $1 q 22-q 25$ & SELE & A153C & 5361 & 0.11 & 0.33 \\
\hline $1 q 31-32$ & IL 10 & C8700A & 1800872 & 0.24 & 0.29 \\
\hline $2 q 12-q 21$ & $I L 1 a$ & C549T & 1800587 & 0.31 & 0.08 \\
\hline \multirow[t]{2}{*}{$2 q 14$} & $I L 1 \beta$ & C4336T & 1143634 & 0.26 & 0.58 \\
\hline & & C1423T & 16944 & 0.34 & 0.49 \\
\hline $2 q 33$ & CTLA4 & C875T & 5742909 & 0.10 & 0.34 \\
\hline $2 q 33$ & CTLA4 & $\mathrm{A} 1241 \mathrm{G}$ & 231775 & 0.40 & 0.68 \\
\hline $3 p 21$ & $C C R 2$ & G46295A & 1799864 & 0.08 & 0.88 \\
\hline \multirow[t]{2}{*}{$3 p 21$} & CCR5 & Wt/del 580-611 & 333 & 0.14 & 0.72 \\
\hline & & G59029A & 1799987 & 0.44 & 0.33 \\
\hline $3 p 21.3$ & $C C R 3$ & C320T & 5742906 & 0.01 & $-\dagger$ \\
\hline 3p26-p24 & IL5RA & G482A & 2290608 & 0.28 & 0.10 \\
\hline \multirow[t]{2}{*}{$4 q 12-q 13$} & $G C$ & G35706T & 7041 & 0.44 & 0.50 \\
\hline & $G C$ & C35717A & 4588 & 0.29 & 0.21 \\
\hline $5 q 22-32$ & $C D 14$ & $\mathrm{C} 2232 \mathrm{~T}$ & 2569190 & 0.47 & 0.63 \\
\hline $5 q 23-q 31$ & IL4 & C582T & 2243250 & 0.14 & 0.66 \\
\hline $5 q 31$ & IL 13 & C4045T & 1295686 & 0.20 & 0.78 \\
\hline $5 q 31$ & TCF7 & C883A & 5742913 & 0.12 & 0.35 \\
\hline
\end{tabular}


Table 3: Tests of association between SNPs and CAD using FBAT. (Continued)

\begin{tabular}{|c|c|c|c|c|c|}
\hline $5 q 31.1$ & TCF7 & A383T & 25882 & 0.14 & 0.49 \\
\hline $5 q 31.1$ & CSF2 & T2600C & 244656 & 0.22 & 0.16 \\
\hline \multirow[t]{3}{*}{$5 q 31-q 32$} & $A D R B 2$ & A1633G & 1042713 & 0.37 & 0.91 \\
\hline & & C1666G & 1042714 & 0.42 & 0.37 \\
\hline & & C2078T & 1800888 & 0.02 & $-t$ \\
\hline $5 q 31-q 35$ & IL9 & C4244T & 2069885 & 0.13 & $0.01(T)$ \\
\hline $5 q 35$ & LTC4S & A620C & 730012 & 0.31 & 0.22 \\
\hline \multirow[t]{3}{*}{$6 p 21.3$} & $L T A$ & A1069G & 909253 & 0.39 & 0.60 \\
\hline & $T N F$ & G3787A & 1800629 & 0.21 & 0.34 \\
\hline & & G3857A & 361525 & 0.07 & 0.99 \\
\hline \multirow[t]{2}{*}{ 7p21-p15 } & IL6 & G589C & 1800796 & 0.06 & 0.33 \\
\hline & & G987C & 1800795 & 0.43 & 0.38 \\
\hline \multirow[t]{2}{*}{$7 q 35-q 36$} & NOS3 & A498G & 1800779 & 0.40 & 0.05 (G) \\
\hline & & G7002T & 1799983 & 0.36 & 0.67 \\
\hline $9 q 32-q 34$ & $C 5$ & $A 2416 G$ & 17611 & 0.44 & 0.04 (G) \\
\hline $10 q 11.1$ & SDF1 & G880A & 1801157 & 0.20 & 0.84 \\
\hline 11q11-qter & $U G B$ & G587A & 3741240 & 0.36 & 0.65 \\
\hline $11 q 13$ & FCERB1 & A7297G & 569108 & 0.03 & 0.48 \\
\hline \multirow[t]{2}{*}{$12 q 13.1$} & $V D R$ & $\mathrm{~T} 12022 \mathrm{C}$ & 2228570 & 0.40 & 0.77 \\
\hline & & G45082A & 1544410 & 0.42 & 0.61 \\
\hline \multirow[t]{2}{*}{ 16p11.2-p12.1 } & $I L 4 R$ & A398G & 1805010 & 0.46 & 0.56 \\
\hline & & T1682C & 1805015 & 0.20 & $0.01(C)$ \\
\hline
\end{tabular}


Table 3: Tests of association between SNPs and CAD using FBAT. (Continued)

\begin{tabular}{|c|c|c|c|c|c|}
\hline & & A1902G & 1801275 & 0.25 & 0.04 (G) \\
\hline $17 q 11.2-q 12$ & $\operatorname{NOS} 2 A$ & $\mathrm{C} 231 \mathrm{~T}$ & 1137933 & 0.23 & 0.98 \\
\hline \multirow[t]{2}{*}{$17 q 21.1-q 21.2$} & SCYA11 & G361A & 3744508 & 0.19 & $0.04(G)$ \\
\hline & & G1169A & 4795895 & 0.20 & 0.47 \\
\hline $19 q 13.1$ & TGFB1 & С629T & 1800469 & 0.27 & $-\neq$ \\
\hline \multirow[t]{2}{*}{ 19p13.2 } & ICAM1 & A120T & 5491 & 0.001 & $-\neq$ \\
\hline & & G657A & 1799969 & 0.12 & 0.43 \\
\hline 19p13.3-p13.2 & C3 & C364G & 2230199 & 0.24 & 0.39 \\
\hline
\end{tabular}

that the haplotype ILI-CCC may increase the risk of CAD through increasing the risk of hypercholesterolaemia, although the high correlation between hypercholesterolaemia and CAD in our study makes this difficult to evaluate.

\section{Discussion}

We present here the results of an association analysis of CAD with multiple inflammatory genes in one of the UK's largest discordant sibship studies. This family-based cohort avoids the potential bias of population stratification and admixture that may affect even a well designed case-control study [14]. The haplotype analysis maximized the use of family information and accommodated phase uncertainty. Our strongest finding was a suggested association with a common haplotype in the interleukin 1 gene cluster (ILICCC, see Table 4), particularly in those individuals with younger onset $\mathrm{CAD}$. The per-copy $\mathrm{OR}$ for $\mathrm{CAD}$ was 1.21 (unadjusted $P=0.01$ ), rising to 1.50 in younger affecteds (unadjusted single haplotype test $P=0.0001$ and overall test $P=0.02$ ). The effect of this haplotype on early-onset disease risk remained significant after adjusting for covariates other than hypercholesterolaemia $(\mathrm{OR}=1.53, P=$ 0.002 , Table 5). However, including hypercholesterolaemia in the model greatly reduced the estimated effect. The effect of ILI-CCC on hypercholesterolaemia was found to be of similar magnitude as on CAD itself, suggesting that ILICCC may actually increase the risk to CAD through increasing the risk of hypercholesterolaemia.
The relationship between hypercholesterolaemia and CAD is well established. At present, no direct evidence of correlation between $I L-1$ and hypercholesterolaemia exists in man. Mice lacking interleukin-1 receptor antagonist (ILIRA) display significant derangement of cholesterol homeostasis in response to an atherogenic diet [15]. Furthermore, studies in hypercholesterolemic mice suggest that lack of $I L-1 \beta$ or over-expression of ILIRA can partly protect against atherosclerosis [16]. Accordingly, elevation of $I L-1$ is consistently observed in individuals with unstable CAD and predicts mortality post MI [17]. The use of HMGCoA inhibitors (statins), known to reduce lipoprotein levels and risk of cardiovascular events, has been shown to reduce mRNA levels of both $I L 1 \alpha$ and $I L 1 \beta$ in peripheral blood mononuclear cells (PBMCs) [17] providing further evidence of an interplay between $I L-1$ and hypercholesterolaemia.

Ikonomidis et al. [18] have evaluated the immediate and short-term effects of anakinra, a recombinant IL1 receptor antagonist, on coronary flow; left ventricular (LV) and endothelial function and mediators of inflammation. In patients with rheumatoid arthritis and no evidence of CAD/ ischaemia, anakinra resulted in both an acute and sustained improvement in left ventricular function, endothelial function and coronary flow reserve with a reduction in IL-6 and endothelin-1, compared to placebo/prednisolone. Relatively small numbers of patients were studied and those with CAD were specifically excluded. It remains unclear, therefore, 
Table 4: Haplotype association to CAD, CAD before age 50 (CAD50) or MI.

\begin{tabular}{|c|c|c|c|c|c|c|c|c|}
\hline Gene & SNP & $\begin{array}{l}\text { Position } \\
*\end{array}$ & LDt & Hap‡ & Freq§ & P_CAD & P_MI & P_CAD50 \\
\hline \multirow[t]{2}{*}{ IL1a } & C549T & $\begin{array}{l}11325943 \\
1\end{array}$ & & $\mathrm{CCC}$ & 0.41 & $0.006(+)$ & $0.01(+)$ & $\begin{array}{l}0.0002 \\
(+)\end{array}$ \\
\hline & & & 0.78 & $\mathrm{CCT}$ & 0.26 & 0.60 & 0.96 & 0.32 \\
\hline \multirow[t]{2}{*}{$I L 1 \beta$} & C4336T & $\begin{array}{l}11330686 \\
1\end{array}$ & & CTC & 0.17 & 0.30 & 0.06 & 0.31 \\
\hline & & & 0.67 & TCC & 0.06 & 0.08 & 0.30 & 0.08 \\
\hline \multirow[t]{5}{*}{$I L 1 \beta$} & C1423T & 11331133 & & $\mathrm{TCT}$ & 0.04 & 0.45 & - & 0.37 \\
\hline & & & & CTC & 0.03 & 0.69 & - & - \\
\hline & & & & ताT & 0.02 & - & - & - \\
\hline & & & & $\mathrm{CTT}$ & 0.01 & - & - & - \\
\hline & & & & All (7df) & - & 0.13 & 0.25 & 0.02 \\
\hline \multirow[t]{3}{*}{ NOS3 } & A498G & 15032087 & & AG & 0.50 & 0.77 & 0.84 & 0.63 \\
\hline & & 6 & & & & & & \\
\hline & & & 0.47 & GT & 0.23 & 0.24 & 0.32 & 0.40 \\
\hline \multirow[t]{3}{*}{ NOS3 } & G7002T & 15032704 & & GG & 0.16 & 0.16 & 0.11 & 0.36 \\
\hline & & & & AT & 0.11 & $0.009(-)$ & $0.005(-)$ & 0.15 \\
\hline & & & & All (3df) & - & 0.04 & 0.03 & 0.39 \\
\hline \multirow[t]{2}{*}{ SCYA11 } & G361A & 29637007 & & $\mathrm{GG}$ & 0.66 & $0.05(+)$ & 0.10 & $0.02(+)$ \\
\hline & & & 1.00 & GA & 0.18 & 0.84 & 0.73 & 0.29 \\
\hline \multirow[t]{3}{*}{ SCYA11 } & G1169A & 29635559 & & $A G$ & 0.16 & $0.02(-)$ & 0.09 & 0.06 \\
\hline & & & & $A A$ & 0.00 & - & - & - \\
\hline & & & & All (2df) & - & 0.05 & 0.17 & 0.06 \\
\hline
\end{tabular}


Table 4: Haplotype association to CAD, CAD before age 50 (CAD50) or MI. (Continued)

\begin{tabular}{|c|c|c|c|c|c|c|c|c|}
\hline \multirow[t]{2}{*}{ IL4R } & \multirow[t]{2}{*}{ A398G } & \multirow[t]{2}{*}{27263704} & & ATA & 0.45 & 0.16 & 0.36 & 0.15 \\
\hline & & & 0.37 & GTA & 0.33 & 0.44 & 0.46 & 0.63 \\
\hline \multirow[t]{2}{*}{ IL4R } & T1682C & 27281681 & & GCG & 0.11 & $0.04(+)$ & 0.24 & 0.56 \\
\hline & & & 1.00 & ACG & 0.06 & 0.22 & 0.49 & 0.20 \\
\hline \multirow[t]{5}{*}{ IL4R } & A1902G & 27281901 & & ATG & 0.03 & 0.91 & 0.60 & $0.03(+)$ \\
\hline & & & & GTG & 0.02 & - & - & - \\
\hline & & & & GCA & 0.002 & - & - & - \\
\hline & & & & $A C A$ & 0.001 & - & - & - \\
\hline & & & & All (7df) & - & 0.88 & 0.41 & 0.17 \\
\hline
\end{tabular}

*Physical position (base pairs) from NCBI dbSNP build 128.

† Absolute value of the linkage disequilibrium (LD) coefficient D' between consecutive single nucleotide polymorphisms (SNPs).

₹ Results only shown for haplotypes having a number of informative families $>50$.

§Haplotype frequencies estimated in the total sample.

$+(-)$, Haplotype associated with increased (decreased) disease risk; CAD, coronary artery disease; MI, myocardial infarction; SNP, single nucleotide polymorphism.

whether these findings have any relevance to those with $\mathrm{CAD} /$ without rheumatoid arthritis. In particular, are the changes in LV and endothelial function reversible when ischaemic in aetiology and are the inflamed joints of active rheumatoid arthritis a prerequisite for anakinra to have an effect? In animal models, acute anakinra administration does appear to reduce cardiomyocyte apoptosis and adverse remodelling [19]. Further clarity is likely to be added by the Medical Research Council funded ILA HEART study [20] evaluating anakinra in patients presenting with a MI.

The ILI $\beta$ polymorphism C1423T has been investigated previously in relation to $\mathrm{CAD}$, with mixed results. An excess of CC genotypes was reported in affected individuals compared to unaffecteds ( $22 \%$ versus $13 \%)$, although this difference was not significant [21]. Another study [22] subsequently found no evidence of difference in allele frequencies on this SNP between subjects with angiographically normal and abnormal coronary arteries. By contrast, Iacoviello et al. [23] found a significantly reduced risk of MI and ischaemic stroke at young age $(<45$ years for men and $<50$ for women) in carriers of the $\mathrm{T}$ allele after adjustment of the traditional risk factors. They also demonstrated that mononuclear cells in carriers of the $\mathrm{T}$ allele produce significantly lower $I L-1 \beta$ levels than in non-carriers. However, the same $\mathrm{T}$ allele was found significantly associated with increased risk of atherogenesis in subclavian arteries in a cohort of elderly Japanese [24].

In our study, no association was found between the $I L 1 \beta$ C1423T SNP and CAD, but we did detect an association with a haplotype containing this SNP. These results suggest that the SNP itself may not increase the risk of CAD but may be in strong LD with a causal variant, which may also partially explain inconsistencies in results across different studies. It is also possible that it is the haplotype that influences CAD rather than one nucleotide change. Chen et al. [25] showed that SNP alleles in ILI $\beta$ have increased transcriptional activity when combined (into haplotypes) and suggested that it may be a common feature of gene regulatory regions. ILI gene cluster haplotypes have been found associated with many diseases, including schizophrenia and bipolar disorder [26], gastric cancer [27] and psoriatic arthritis [28]. In the case of CAD, age of onset appears to be an important factor (our study and [23]).

The $I L 1 \alpha$ and $I L 1 \beta$ genes lie on chromosome 2 about 15 $\mathrm{Mb}$ centromeric to the linkage peak found in a large UK study of sibling pairs affected with CAD [29]. The evidence 
Table 5: Joint effects of the IL 1-CCC haplotype and other risk factors on CAD.

\begin{tabular}{|c|c|c|c|c|c|}
\hline Trait & Factor & P_value & Odds ratio & $95 \mathrm{Cl}^{*}$ & \\
\hline \multirow[t]{5}{*}{ CAD } & IL 1 CCC & 0.047 & 1.22 & 1.00 & 1.47 \\
\hline & $\begin{array}{l}\text { Sex (baseline }=\text { fe- } \\
\text { male) }\end{array}$ & $<0.001$ & 4.86 & 4.00 & 5.91 \\
\hline & Ever smoked & $<0.001$ & 2.01 & 1.62 & 2.50 \\
\hline & Hypertension & $<0.001$ & 3.16 & 2.55 & 3.92 \\
\hline & Overall test (4df) & $P<0.0001$ & & & \\
\hline \multirow{5}{*}{$\begin{array}{l}\text { CAD before } 50 \\
\text { years }\end{array}$} & ILICCC & 0.002 & 1.53 & 1.17 & 2.01 \\
\hline & $\begin{array}{l}\text { Sex (baseline }=\mathrm{fe}- \\
\text { male) }\end{array}$ & $<0.001$ & 6.44 & 4.78 & 8.67 \\
\hline & Ever smoked & $<0.001$ & 3.03 & 2.16 & 4.26 \\
\hline & Hypertension & $<0.001$ & 3.57 & 2.56 & 5.00 \\
\hline & Overall test (4df) & $P<0.0001$ & & & \\
\hline
\end{tabular}

* $95 \%$ confidence interval $(\mathrm{Cl})$

$\mathrm{CAD}$, coronary artery disease.

for linkage in this region was much stronger in the subset of sibling pairs without hypercholesterolaemia, although when this covariate was included in the analysis the main linkage peak shifted slightly further away from the $I L 1$ gene cluster [30]. It is well known that the highest linkage peak may be at a considerable distance from the disease-causing locus, especially when based on relative pair analyses, so it is possible that the ILI cluster contributed to the evidence of linkage.

Our second interesting finding was in the gene NOS3 on chromosome 7. Many studies have reported an association between the G7002T SNP in this gene (also referred to as $894 \mathrm{G} / \mathrm{T}$ or Glu298Asp) and a number of diseases including CAD/MI [31,32] and essential hypertension [33,34]. However, most of these studies were based on unrelated casecontrol designs with a limited size. While our larger study does not confirm the association of this SNP with CAD $(P$ $=0.67$, Table 3 ), we did observe a weak association between CAD and a promoter region SNP (A498G, $P=$
0.05, Table 3) whilst a haplotype spanning the two SNPs showed a stronger association (single haplotype test $P=$ 0.009 for $\mathrm{CAD}$ and $P=0.005$ for $\mathrm{MI}$, overall haplotype test $P=0.04$ for CAD and $P=0.03$ for MI, Table 4). The AT haplotype appears to reduce the risk of CAD and $\mathrm{MI}$, although this was not confirmed in patients affected at younger age. Although the polymorphism G7002T changes the protein sequence (Glu298Asp), its actual functional significance is not well understood [33] and our results suggest again that a haplotype or an untyped SNP may be of relevance.

Other SNPs or haplotype associations marginally significant in this study were found in IL9, C5, IL4R and SCYA11 (Tables 3 and 4). Their significance was much lower than that of IL1 cluster and NOS3, and given the number of tests performed, they are more likely to be false positives. The IL 1 cluster and NOS3 associations may also be due to type 1 errors and do not reach 5\% statistical significance if adjusted for the number of tests performed. However, for 
the ILI gene cluster, the consistency with prior findings $[21,23,24,29,30]$ and the increased risk observed in younger subjects increase the likelihood that this is a true association, and the family-based design of our study provides reassurance against confounding by population stratification. Further investigation of a denser set of SNPs in this region in larger samples of patients and controls is needed for confirmation.

\section{Additional material}

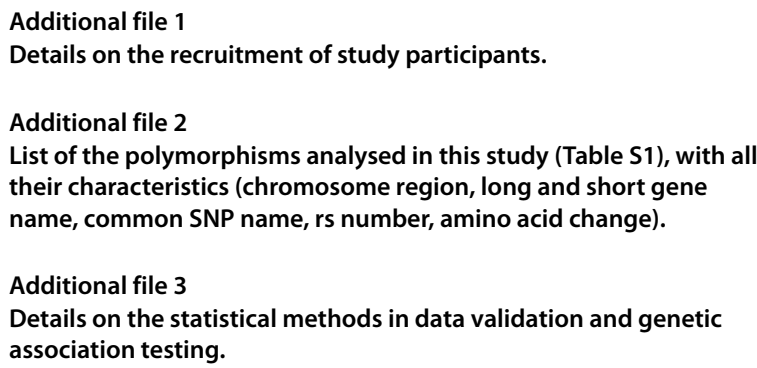

\section{Abbreviations}

BMI: body mass index; CABG: coronary artery bypass surgery; CAD: coronary artery disease; CLR: conditional logistic regression; FBAT: family-based association test; LD: linkage disequilibrium; LV: left ventricular; MI: myocardial infarction; PCR: polymerase chain reaction; PTCA: percutaneous transluminal coronary angioplasty; SNP: single nucleotide polymorphism.

\section{Competing interests}

The authors declare that they have no competing interests.

\section{Authors' contributions}

The authors' contributions to this study were as follows: design/planning ASH, NJS, SGB, DTB, AJB and JHB; study set-up - BDB and RAL; SNPs selection/ assay production - SC and LS; lab supervision - AJB; statistical analyses - JN and $J H B$; paper drafting - BDB, JN and JHB; overall supervision - ASH. All the authors read and approved the manuscript.

\section{Acknowledgements}

This research was supported by the British Heart Foundation (BHF) and the UK National Health Services Research and Development (NHS R\&D). We thank all the families who participated in the study, as well as the staff in hospitals and general practices who helped in the collection of samples and the validation of medical records.

\section{Author Details}

'Leeds Institute of Genetics, Health and Therapeutics (LIGHT), University of Leeds, UK,

2Leeds Institute of Molecular Medicine (LIMM), University of Leeds, UK,

${ }^{3}$ Roche Molecular Systems, Pleasanton, California, USA and

${ }^{4}$ Department of Cardiovascular Sciences, University of Leicester, UK

Received: 27 November 2009 Accepted: 13 January 2010 Published: 13 January 2010

\section{References}

1. Ross R: Atherosclerosis-an inflammatory disease. N Engl J Med 1999, 340:115-125

2. Lusis JA, Mar R, Pajukanta P: Genetics of atherosclerosis. Annu Rev Genomics Hum Genet 2004, 5:189-218.
3. Barcellos LF, Begovich AB, Reynolds RL, Caillier SJ, Brassat D, Schmidt S, Grams SE, Walker K, Steiner LL, Cree BAC, Stillman A, Lincoln RR, PericakVance MA, Haines JL, Erlich HA, Hauser SL, Oksenberg JR: Linkage and association with the NOS2A locus on chromosome $17 q 11$ in multiple sclerosis. Ann Neurol 2004, 55:793-800.

4. Abecasis GR, Cherny SS, Cookson WO, Cardon LR: GRR: graphical representation of relationship errors. Bioinformatics 2001, 17:742-743.

5. Goring HH, Ott J: Relationship estimation in affected sib pair analysis of late-onset diseases. Eur J Hum Genet 1997, 5:69-77.

6. Boehnke M: Allele frequency estimation from data on relatives. Am J Hum Genet 1991, 48:22-25.

7. Rabinowitz D, Laird NM: A unified approach to adjusting association tests for population admixture with arbitrary pedigree structure and arbitrary missing marker information. Hum Hered 2000, 50:211-223.

8. Lake SL, Blacker D, Laird NM: Family-based tests of association in presence of linkage. Am J Hum Genet 2000, 67:1515-1525.

9. STATA Corp: Stata Statistical Software: Release 9. TX: StataCorp LP. 2005.

10. Siegmund KD, Langholz B, Kraft P, Thomas DC: Testing linkage disequilibrium in sibships. Am J Hum Genet 2000, 67:244-248.

11. Nsengimana J, Barrett $\mathrm{JH}$ : Power, validity, bias and robustness of familybased association analysis methods in the presence of linkage for late onset diseases. Ann Hum Genet 2008, 72:793-800.

12. Zhang $\mathrm{K}$, Sun F, Zhao H: HAPLORE: a program for haplotype reconstruction in general pedigrees without recombination. Bioinformatics 2005, 21:90-103.

13. Zaykin DV, Westfall PH, Young SS, Karnoub MA, Wagner MJ, Ehm MG: Testing association of statistically inferred haplotypes with discrete and continuous traits in samples of unrelated individuals. Hum Hered 2002, 53:79-91.

14. Freedman ML, Reich D, Penney KL, McDonald GJ, Mignault AA, Patterson N, Gabriel SB, Topol EJ, Smoller JW, Pato CN, Pato MT, Petryshen TL, Kolonel LN, Lander ES, Sklar P, Henderson B, Hirschhorn JN, Altshuler D: Assessing the impact of population stratification on genetic association studies. Nat Genet 2004, 36:388-393.

15. Isoda K, Sawada S, Ayaori M, Matsuki T, Horai R, Kagata Y, Miyazaki K, Kusuhara M, Okazaki M, Matsubara O, Iwakura Y, Ohsuzu F: Deficiency of interleukin-1 receptor antagonist deteriorates fatty liver and cholesterol metabolism in hypercholesterolemic mice. J Biol Chem 2005, 280:7002-7009.

16. Kirii H, Niwa T, Yamada Y, Wada H, Saito K, Iwakura Y, Asano M, Moriwaki H, Seishima M: Lack of interleukin-1 beta decreases the severity of atherosclerosis in ApoE-deficient mice. Arterioscler Thromb Vasc Biol 2003, 23:656-660

17. Waehre T, Yndestad A, Smith C, Haug T, Tunheim SH, Gullestad L, Froland SS, Semb AG, Aukrust P, Damas JK: Increased expression of interleukin-1 in coronary artery disease with downregulatory effects of hmg-coa reductase inhibitors. Circulation 2004, 109:1966-1972.

18. Ikonomidis I, Lekakis JP, Nikolaou M, Paraskevaidis I, Andreadou I, Kaplanoglou T, Katsimbri P, Skarantavos G, Soucacos PN, Kremastinos DT: Inhibition of interleukin-1 by anakinra improves vascular and left ventricular function in patients with rheumatoid arthritis. Circulation 2008, 117:2662-2669.

19. Abbate A, Salloum FN, Vecile E, Das A, Hoke NN, Straino S, Biondi-Zoccai GG, Houser JE, Qureshi IZ, Ownby ED, Gustini E, Biasucci LM, Severino A, Capogrossi MC, Vetrovec GW, Crea F, Baldi A, Kukreja RC, Dobrina A: Anakinra, a recombinant human interleukin-1 receptor antagonist, inhibits apoptosis in experimental acute myocardial infarction. Circulation 2008, 117:2670-83.

20. Crossman DC, Morton AC, Gunn JP, Greenwood JP, Hall AS, Fox KA, Lucking AJ, Flather MD, Lees B, Foley CE: Investigation of the effect of interleukin-1 receptor antagonist (IL-1 ra) on markers of inflammation in non-ST elevation acute coronary syndromes (the MRC-ILA-HEART Study). Trials 2008, 9:8.

21. Momiyama $Y$, Hirano R, Taniguchi H, Nakamura H, Ohsuzu F: Effects of interleukin-1 gene polymorphisms on the development of coronary artery disease associated with Chlamydia pneumoniae infection. J Am Coll Cardiol 2001, 38:712-717.

22. Vohnout B, Di Castelnuovo CA, Trotta R, D'Orazi A, Panniteri G, Montali A, Donati MB, Arca M, lacoviello L: Interleukin-1 gene cluster polymorphisms and risk of coronary artery disease. Haematologica 2003, 88:54-60. 
23. lacoviello L, Di Castelnuovo A, Gattone M, Pezzini A, Assanelli D, Lorenzet R, Del Zotto E, Colombo M, Napoleone E, Amore C, D'Orazio A, Padovani A, de Gaetano G, Giannuzzi P, Donati MB, IGIGI Investigators:

Polymorphisms of the interleukin-1 beta gene affect the risk of myocardial infarction and ischaemic stroke at young age and the response of mononuclear cells to stimulation in vitro. Arterioscler Thromb Vasc Biol 2005, 25:222-227.

24. Oda K, Tanaka N, Arai T, Araki J, Song Y, Zhang L, Kuchiba A, Hosoi T, Shirasawa T, Muramatsu M, Sawabe M: Polymorphisms in pro- and antiinflammatory cytokine genes and susceptibility to atherosclerosis: a pathological study of 1503 consecutive autopsy cases. Hum Mol Genet 2007, 16:92-599.

25. Chen H, Wilkins LM, Aziz N, Cannings C, Wyllie DH, Bingle C, Rogus J, Beck JD, Offenbacher S, Cork MJ, Rafie-Kolpin M, Hsieh CM, Kornman KS, Duff GW: Single nucleotide polymorphisms in the human interleukin-1B gene affect transcription according to haplotype context. Hum Mol Genet 2006, 15:519-529.

26. Papiol S, Rosa A, Gutiérrez B, Martin B, Salgado P, Catalán R, Arias B, Fañanás L: Interleukin-1 cluster is associated with genetic risk for schizophrenia and bipolar disorder. J Med Genet 2004, 41:219-223.

27. El-Omar EM, Carrington M, Chow WH, McColl KE, Bream JH, Young HA, Herrera J, Lissowska J, Yuan CC, Rothman N, Lanyon G, Martin M, Fraumeni JF Jr, Rabkin CS: Interleukin-1 polymorphisms associated with increased risk of gastric cancer. Nature 2000, 404:398-402.

28. Rahman P, Sun S, Peddle L, Snelgrove T, Melay W, Greenwood C, Gladman D: Association between the interleukin-1 family gene cluster and psoriatic arthritis. Arthritis Rheum 2006, 54:2321-2325.

29. The BHF Family Heart Study Research Group: A genomewide linkage study of 1,933 families affected by premature coronary artery disease: the British Heart Foundation (BHF) family heart study. Am J Hum Genet 2005, 77:1011-1020

30. Nsengimana J, Samani NJ, Hall AS, Balmforth AJ, Mangino M, Yuldasheva N, Magbool A, Braund P, Burton P, Bishop DT, Ball SG, Barrett JH, British Heart Foundation Family Heart Study Research Group: Enhanced linkage of a locus on chromosome 2 to premature coronary artery disease in the absence of hypercholesterolaemia. Eur J Hum Genet 2006, 15:313-319.

31. Shimasaki Y, Yasue $H$, Yoshimura M, Nakayama M, Kugiyama K, Ogawa $H$, Harada E, Masuda T, Koyama W, Saito Y, Miyamoto Y, Ogawa Y, Nakao K: Association of the missense glu298asp variant of the endothelial nitric oxide synthase gene with myocardial infarction. J Am Coll Cardiol 1998, 31:1506-1510.

32. Hingorani AD, Liang CF, Fatibene J, Lyon A, Monteith S, Parsons A, Haydock S, Hopper RV, Stephens NG, O'Shaughnessy KM, Brown MJ: A common variant of the endothelial nitric oxide synthase (glu298->asp) is a major risk factor for coronary artery disease in the UK. Circulation 1999, 100:1515-1520.

33. Jachymova M, Horky K, Bultas J, Kozich V, Jindra A, Peleska J, Martasek P: Association of the glu298asp polymorphism in the endothelial nitric oxide synthase gene with essential hypertension resistant to conventional therapy. Biochem Biophys Res Commun 2001, 284:426-430.

34. Shoji M, Tsutaya S, Saito R, Takamatu H, Yasujima M: Positive association of endothelial nitric oxide synthase gene polymorphism with hypertension in Northern Japan. Life Sciences 2000, 66:2557-2662.

\section{Pre-publication history}

The pre-publication history for this paper can be accessed here: http://www.biomedcentral.com/1741-7015/8/5/prepub

\section{doi: 10.1186/1741-7015-8-5}

Cite this article as: Brown et al, An evaluation of inflammatory gene polymorphisms in sibships discordant for premature coronary artery disease: the GRACE-IMMUNE study BMC Medicine 2010, 8:5 